\title{
Análise de impacto de balas de borracha em um modelo computacional de olho humano
}

\author{
Marco L. Bittencourt (PQ), Gabriela R. Correa (IC)
}

\section{Resumo}

O projeto constitui na análise computacional dos danos causados pelo impacto de um projetil de borracha em um olho humano, tendo como principal dano o possível descolamento da retina.

Palavras Chave: modelagem, simulação, MEF.

\section{Introdução}

O impacto de um objeto contra o olho causa danos diretos no local em que foi atingido e também danos indiretos a tecidos oculares mais distantes devido à transmissão de forças [1].

Esses traumas podem levar ao descolamento da retina, fato que ocorre quando há o seu desprendimento da coróide, e a consequente não vascularização nas células da retina, deixando-as sem oxigênio e nutrientes. Se não tratada, esta condição pode levar à degeneração celular e resultar na perda da visão [2].

O objetivo deste projeto é estudar casos de impacto de balas de borracha em um modelo de olho humano, com o auxílio do programa comercial ABAQUS® CAE (Computer Aided Engineering).

\section{Resultados e Discussão}

Para o desenvolvimento do projeto foi utilizado o modelo mostrado na Figura 1 desenvolvido por [3], o qual envolve as seguintes estruturas: retina, esclera, corpo ciliar, fibras zonulares, lente e a córnea. Através do estudo da simulação de tal modelo ao sofrer um impacto com um projétil de borracha utilizando o programa ABAQUS ${ }^{\circledR}$ através do Método dos Elementos Finitos foi possível qualitizar o dano à qual um indivíduo está exposto nesta situação.

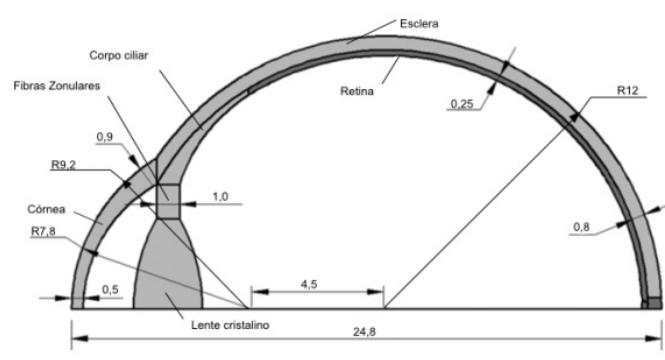

Figura 1. Estruturas e dimensões do modelo abordado. Adaptado de [3].

\section{Conclusões}

Como visto, o projeto alcançou o obtjetivo de modelar o problema em questão e simulá-lo para provar que tal impato ocasionará danos no olho. Devido a problemas de convergência na simulação, não foi possível obter dados numéricos, sendo esse o objetivo para um próximo trabalho.

\section{Agradecimentos}

Concessão da bolsa de Iniciação Científica/PIBIC pelo $\mathrm{CNPq}$ - Conselho Nacional de desenvolvimento científico e tecnológico.

JOHNSTON, P.B.,’Traumatic retinal detachment”. British Journal of Ophthalmology, Vol 75, n.1, pp 18-21. 1991.

\footnotetext{
2 JALALI, S. "Retinal detachment". Community Eye Health, 2003. ${ }^{3}$ LIU, X.; WANG, L. "Mechanism of traumatic retinal detachment in blunt impact: A finite element study". Journal of Biomechanics, Vol 46, pp 1321-1327.2013.
} 